\title{
CpG-DNA derived from sera in systemic lupus erythematosus enhances ICAM-1 expression on endothelial cells
}

\author{
M Miyata, O Ito, H Kobayashi, T Sasajima, H Ohira, S Suzuki, R Kasukawa
}

\begin{abstract}
Objective-To examine the effect of transfection of oligodeoxynucleotides (ODNs) containing a CpG motif (CpG-ODN), of which the sequence was derived from circulating DNA in the sera of patients with systemic lupus erythematosus (SLE), on the expression of intercellular adhesion molecule-1 (ICAM-1) and synthesis of mRNA for proinflammatory cytokines and ICAM-1 in human umbilical vein endothelial cells (EC).

Methods-A CpG-ODN or a control analogue, GpC-ODN, was transfected into EC. ICAM-1 expression was examined by flow cytometry, and expression of mRNA in EC encoding interleukin 1 (IL1), IL6, IL8, tumour necrosis factor $\alpha$ (TNF $\alpha$ ), interferon $\gamma$ (IFN $\gamma)$, and ICAM-1 was examined by semiquantitative reverse transcriptase-polymerase chain reaction. Results-The CpG-ODN augmented the expression of ICAM-1 on EC determined by flow cytometry and increased mRNA levels of IL6, IL8, TNF $\alpha$, IFN $\gamma$, and ICAM-1, but the GpC-ODN did not. Conclusion-Synthesised DNA, with a sequence corresponding to that of the fragment containing the $\mathrm{CpG}$ motif, in sera of patients with SLE was found to enhance ICAM-1 expression on EC, suggesting the participation of circulating DNA fragments in the pathogenesis of vasculitis in SLE.

(Ann Rheum Dis 2001;60:685-689)
\end{abstract}

Microbial DNA and biologically active oligodeoxynucleotides (ODNs) containing a $\mathrm{CpG}$ motif powerfully activate immune cells, such as macrophages and immature dendritic cells, to up regulate their expression of major histocompatibility complex class II and costimulatory molecules, transcribe cytokine mRNAs, and secrete proinflammatory cytokines. ${ }^{12}$

Vasculitis has been believed to be one of the key pathogenic changes in systemic lupus erythematosus (SLE), in which the interaction between endothelial cells (EC) and circulating DNA fragments may be crucial.

From this point of view, an analysis of the characteristics of circulating DNA fragments may provide an important clue in the elucidation of the pathogenesis of SLE. We recently reported that DNA fragments obtained from the sera of patients with active SLE are rich in $\mathrm{G}+\mathrm{C}$ and the $\mathrm{CpG}$ motif. ${ }^{3}$ Unmethylated $\mathrm{CpG}$ motifs are common in microbial DNA, but
CpG motifs in vertebrate DNA are suppressed as well as methylated, except in CpG-rich islands, where they remain unmethylated. ${ }^{4}$ Interestingly, DNA fragments containing the CpG motif in the sera of patients with SLE were found to be immunostimulatory, and we speculated that those DNA fragments were derived from $\mathrm{CpG}$-rich islands, or from genomic DNA, where they are less intensively methylated. ${ }^{3}$

The immunostimulatory properties of $\mathrm{CpG}$ ODNs on EC have not yet been studied. Therefore, we investigated whether or not a CpG-ODN, with a sequence derived from DNA fragments containing the immunostimulatory $\mathrm{CpG}$ motif found in a patient with SLE, is immunostimulatory to human umbilical vein EC. As an initial step in exploring the immunostimulatory properties of $\mathrm{CpG}-\mathrm{ODNs}$ on EC, this study was carried out by transfecting synthesised $\mathrm{CpG}-\mathrm{ODNs}$ using lipofection to enhance the effect of $\mathrm{CpG-ODNs}$ as was shown previously. ${ }^{3}$ We report here that synthetic CpG-ODN is immunostimulatory to EC.

\section{Methods}

PREPARATION OF ODNS

Nuclease resistant phosphorothioate modified ODNs, ${ }^{5}$ as described below, were synthesised using an automated DNA synthesiser (model 394; Perkin Elmer, NJ, USA):

CpG-ODN (KJ-6); 5'-TTTTCAATTCGAA GATGAAT-3'

GpC-ODN (KJ-6); 5'-TTTTCAATTGCAA GATGAAT-3', analogous to CpG-ODN (KJ6), but with the $\mathrm{CpG}$ replaced by GpC.

The sequence of the synthetic $20 \mathrm{bp}$ ODN was derived from DNA purified from the serum of a patient with active SLE as described previously. ${ }^{3}$

CELL PREPARATION AND TREATMENT OF EC WITH ODNS

EC were prepared in accordance with the method of Jaffe et al. ${ }^{6}$ The cells were confirmed as EC by immunofluorescence staining with rabbit antihuman von Willebrand factor antibodies (Dakopatts, Glostrup, Denmark), and there were no contaminated monocytes/ macrophages. The experiments were performed by using EC at two to four passages from five different sources.

ODNs were treated with a lipofection reagent (DOTAP; Boehringer Mannheim, Mannheim, Germany) so that they were effectively incorporated into the EC. ${ }^{7}$ Briefly, an 
ODN solution was gently mixed with an equal volume of lipofection reagent in a polystyrene tube, and the mixture was left to stand for 15 minutes at $25^{\circ} \mathrm{C}$. The ODN solution prepared thus was added to $1 \times 10^{6} \mathrm{EC}$ in a 24 well, flat bottomed plate (Nunc, Roskilde, Denmark) at a final concentration of $0.02,0.2$, and $2 \mu \mathrm{mol} / 1$, and the plates were incubated for three hours for mRNA measurement or for 48 hours for flow cytometric analysis, under $5 \% \mathrm{CO}_{2}$ at $37^{\circ} \mathrm{C}$. The cell viability was over $95 \%$ as determined by the trypan blue dye exclusion method under these conditions. The incubation time and concentration of ODN were chosen based on the results of a previous study of the immunostimulatory effects of $\mathrm{CpG}$ ODNs on monocytes. ${ }^{3}$

FLOW CYTOMETRIC ANALYSIS

EC incubated either with DOTAP alone or with both DOTAP and a synthetic ODN were detached from flasks using $0.001 \%$ trypsin in $0.02 \%$ EDTA. The cells $\left(1 \times 10^{6}\right)$ were analysed by staining with fluorescence isothiocyanate conjugated mouse monoclonal antibody to intercellular adhesion molecule-1 (ICAM-1; Immunotech, Marseille Cedex, France). Isotype matched control mouse IgG was used to eliminate non-specific binding.

PREPARATION OF CDNAS

Total RNA was prepared by the method of Chomczynski and Sacchi $^{8}$ as follows. EC $\left(1 \times 10^{6}\right)$, which had been incubated for three hours at $37^{\circ} \mathrm{C}$ with DOTAP alone or with both DOTAP and a synthetic ODN, were immersed in Isogen-LS (Nippon Gene, Toyama, Japan) and subjected to chloroform extraction. Total RNA was precipitated with isopropanol for five minutes at $-20^{\circ} \mathrm{C}$, washed with $80 \%(\mathrm{v} / \mathrm{w})$ ethanol, and dissolved in an appropriate amount of diethyl pyrocarbonate treated water. cDNAs were synthesised by incubating the RNA with $10 \mathrm{U}$ of reverse transcriptase (RAV2; Takara, Tokyo, Japan) for 90 minutes at $42^{\circ} \mathrm{C}$, in a final volume of $40 \mathrm{ml}$. cDNAs were prepared in five independent experiments using EC from five different sources.

SEMIQUANTITATIVE RT-PCR ANALYSIS FOR EXPRESSION OF IL1, IL6, IL8, TNF $\alpha$, IFN $\gamma$, AND ICAM-1 MRNAS

A semiquantitative reverse transcriptasepolymerase chain reaction (RT-PCR) was used to measure the mRNA levels of each cytokine and ICAM-1 in the EC by the method described by Choi et al. ${ }^{9}$ For PCR, $4 \mu$ l aliquots of each cDNA sample, $1 \mathrm{U}$ of recombinant Taq DNA polymerase (TaKaRa Taq: Takara, Tokyo, Japan), and $10 \mathrm{pmol}$ of each of the primers specific for interleukin 1 (IL1), IL6, IL8, tumour necrosis factor $\alpha(\mathrm{TNF} \alpha)$, interferon $\gamma($ IFN $\gamma)$, ICAM-1, or $\beta_{2}$ microglobulin were added in a final volume of $20 \mu \mathrm{l}$. Each primer pair for IL1, IL6, IL8, TNF $\alpha$, IFN $\gamma$, and ICAM-1 was designated using the excellent computer facility at the European Molecular Biology Laboratory and the GenBank database for searches (Software Development,
Tokyo, Japan). The sequences of the primer pairs were as follows:

IL1 $\beta$ sense primer, 5'-TTT CTG CCT GAA GAA CAG-3' and antisense primer, 5'-GCT CAT GAT TTC TGC TCT GAC A-3'; IL6 sense primer, 5'-CCT TCT CCA CAA GCG CCT TC-3' and antisense primer, 5'-GGC AAG TCT CCT CAT TGA ATC-3'; IL8 sense primer, 5'-TCT GCA CTG TGT GAA GGT GCA GTT-3' and antisense primer, 5'-AAC CCT CTG CAC CCA GTT TTC CTT-3'; TNF $\alpha$ sense primer, 5'-TCT CGA ACC CCG AGT GAC AA-3' and antisense primer, 5'-TAT CTC TCA GCT CCA CAC CCA-3'; IFN $\gamma$ sense primer, 5'-AGT TAT ATC TTG GCT TTT CA-3' and antisense primer, 5'-ACC GAA TAA GTC AGC AGC TT-3'; ICAM-1 sense primer, 5'-ACC TAT GGC AAC GAC TC-3' and antisense primer, 5'-TGG AGT CTG CTG GGA ATT T-3'. The primers used for $\beta_{2}$ microglobulin were the same as those reported by Gussow et al. ${ }^{10}$

The cDNA amount in each sample was quantified by measuring the amount of the PCR product for $\beta_{2}$ microglobulin under electrophoresis, and was standardised to determine the amount of mRNAs for proinflammatory cytokines and ICAM-1.

PCR was performed using the Gene Taq Kit (Nippon Gene, Tokyo, Japan) and a thermal cycler (Cetus; Perkin Elmer, NJ, USA). Conditions for IL1, IL6, IL8 cDNA amplification were 30 cycles of 35 seconds at $95^{\circ} \mathrm{C}$ for the denaturation, 25 seconds at $55^{\circ} \mathrm{C}$ for the annealing, and one minute at $72^{\circ} \mathrm{C}$ for the extension, with a denaturation step for three minutes at $95^{\circ} \mathrm{C}$ before the first cycle and an extension step for 10 minutes at $72^{\circ} \mathrm{C}$ after the 30 cycles. Amplifications of TNF $\alpha$ and IFN $\gamma$ cDNAs were performed using a similar protocol except that the annealing temperature was set at $52^{\circ} \mathrm{C}$. Amplification of ICAM- $1 \mathrm{cDNA}$ was performed using a similar protocol except that annealing was set for two minutes at $55^{\circ} \mathrm{C}$ and extension at $72^{\circ} \mathrm{C}$. Amplification of $\beta_{2}$ microglobulin cDNA was also performed using a similar protocol except that the annealing temperature was set at $60^{\circ} \mathrm{C}$.

For measurement of the amplified products, PCR was performed with an antisense primer of each of the cytokines labelled with ${ }^{32} \mathrm{P}$. The amplified products were subjected to electrophoresis on a $2.5 \%$ agarose gel. The sheet gel was dried and exposed to an imaging plate (Fuji Photo Film, Tokyo, Japan). The intensities of the photostimulated luminescence (PSL) of the radioactivity bands were measured with a Bioimaging Analyser BAS 1000 (Fuji Photo Film). The intensities of the PSL for IL1, IL6, IL8, TNF $\alpha$, IFN $\gamma$, and ICAM-1 were divided by the corresponding intensities of PSL for $\beta_{2}$ microglobulin mRNA (mRNA for IL1, IL6, IL8, TNF $\alpha$, IFN $\gamma$ or ICAM-1/ mRNA for $\beta_{2}$ microglobulin).

Statistical analysis was carried out with the Stat View J-5.0 software package for Apple Macintosh computers. A paired Student's $t$ test was performed and the results are shown in fig 2 . 


\section{Results}

Figure 1 shows representative results for the expression of ICAM-1 on EC transfected with DOTAP alone (A), CpG-ODN (KJ-6) (B), or
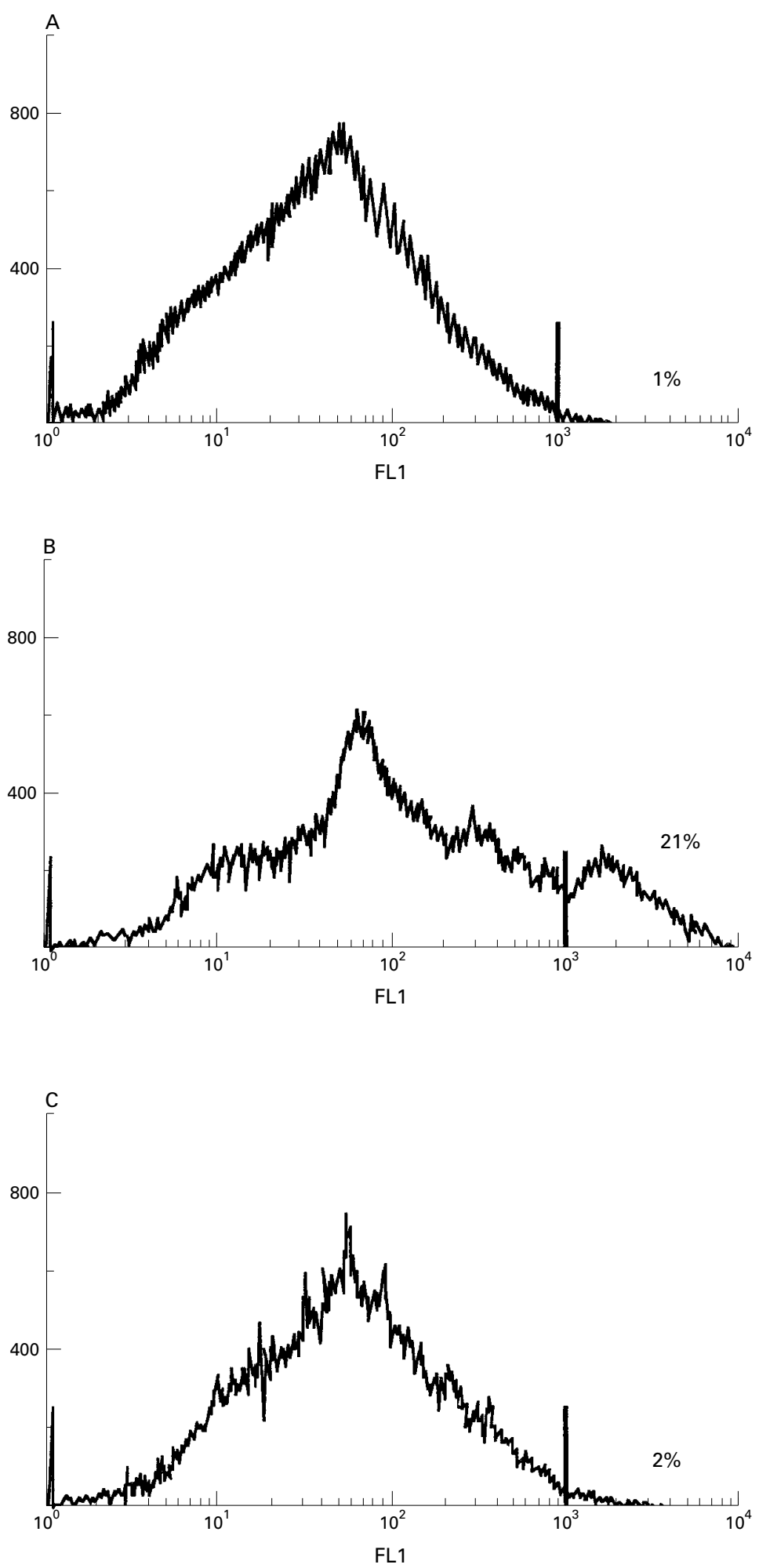

Figure 1 Flow cytometric analysis for intercellular adhesion molecule-1 (ICAM-1) expression on EC transfected with a $C p G-O D N(K \mathcal{F}-6)$ or $G p C-O D N(K \mathcal{F}-6)$. The endothelial cells (EC; $1 \times 10^{6}$ cells) were incubated for 48 hours with DOTAP alone $(A)$, DOTAP and $0.2 \mu \mathrm{mol} / \mathrm{l}$ of CPG-ODN (Kf-6) (B), or DOTAP and $0.2 \mu \mathrm{mol} / \mathrm{l}$ of $G p C-O D N(K \mathcal{F}-6)(C)$, and the ICAM-1 expression was determined by flow cytometric analysis as described in "Methods". Fluorescence intensity and relative cell number are displayed on the horizontal axis and on the vertical axis, respectively. A representative result of five independent experiments using EC from five different sources is shown.
GpC-ODN (KJ-6) (C). A marked increase in ICAM-1 expression was seen on EC transfected with CpG-ODN (KJ-6) (21\%) compared with those treated with DOTAP alone $(1 \%)$ or transfected with GpC-ODN (KJ-6) $(2 \%)$. A significant increase in ICAM-1 expression was not seen on EC transfected with CpG-ODN (KJ-6) in 24 hours (data not shown).

Figure 2 shows the mRNA levels for IL1, IL6, IL8, TNF $\alpha$, IFN $\gamma$, and ICAM-1 in EC treated with DOTAP alone, and those transfected with GpC-ODN (KJ-6) or CpG-ODN (KJ-6).

Neither transfection with CpG-ODN (KJ-6) nor that with GpC-ODN (KJ-6) increased the mRNA levels for IL1.

The mRNA levels for IL6 and IL8 increased from 0.25 and 1.0 to 2.6 and 7.9 , respectively, after transfection with $\mathrm{CpG}-\mathrm{ODN}(\mathrm{KJ}-6)$ at a concentration of $0.2 \mu \mathrm{mol} / 1 \quad(\mathrm{p}<0.05$ and $\mathrm{p}<0.01$, respectively). On the other hand, the levels for IL6 and IL8 showed no significant increase after GpC-ODN (KJ-6) transfection.

The mRNA levels for $\mathrm{TNF} \alpha$ and $\mathrm{IFN} \gamma$ increased from 0.3 and 0.1 to 1.9 and 1.5 $\mu \mathrm{mol} / \mathrm{l}$, respectively, after transfection with CpG-ODN (KJ-6) at a concentration of 0.2 $\mu \mathrm{mol} / 1$ ( $\mathrm{p}<0.05$ for both). On the other hand, no significant increase of the mRNA levels was seen after GpC-ODN (KJ-6) transfection.

According to the results of flow cytometric analysis, the mRNA level for ICAM-1 increased from 0.15 to 2.2 after transfection with CpG-ODN (KJ-6) at a concentration of 0.2 $\mu \mathrm{mol} / 1 \quad(\mathrm{p}<0.01)$, but the level showed no significant increase after GpC-ODN (KJ-6) transfection.

\section{Discussion}

The molecular mechanisms underlying the activation of cells of the immune system by CpG-ODN are poorly understood. However, there is evidence that CpG-ODN binds to cell surface receptors on B cells, which subsequently transduce stimulatory signals. ${ }^{11}$ To the best of our knowledge, cell surface receptors on EC have not been reported.

We presumed that the stimulatory effects of CpG-ODN on EC would be less than those on monocytes/macrophages/B cells because EC may have much less ability to phagocytose ODNs than monocytes/macrophages/B cells. Consequently, we used DOTAP to treat EC with ODNs in order to enhance the effect of CpG-ODN on EC. We assume that DNA/antiDNA immune complexes may bind through either $\mathrm{Fc}$ receptors or $\mathrm{C} 1 \mathrm{q}$ receptors and are incorporated into the EC in vivo. Moreover, macrophages around EC, which have low density lipoprotein receptors and have a scavenging role something like low density lipoprotein and immune complexes, may be implicated in the interaction between DNA/anti-DNA immune complexes and EC.

Furthermore, CpG-ODN may generate reactive oxygen species before nuclear factor $\kappa \mathrm{B}$ activation. ${ }^{12}$ Activation of cells in the immune system by $\mathrm{CpG}-\mathrm{ODN}$ is considered to be mediated, at least in part, by the stress kinase 


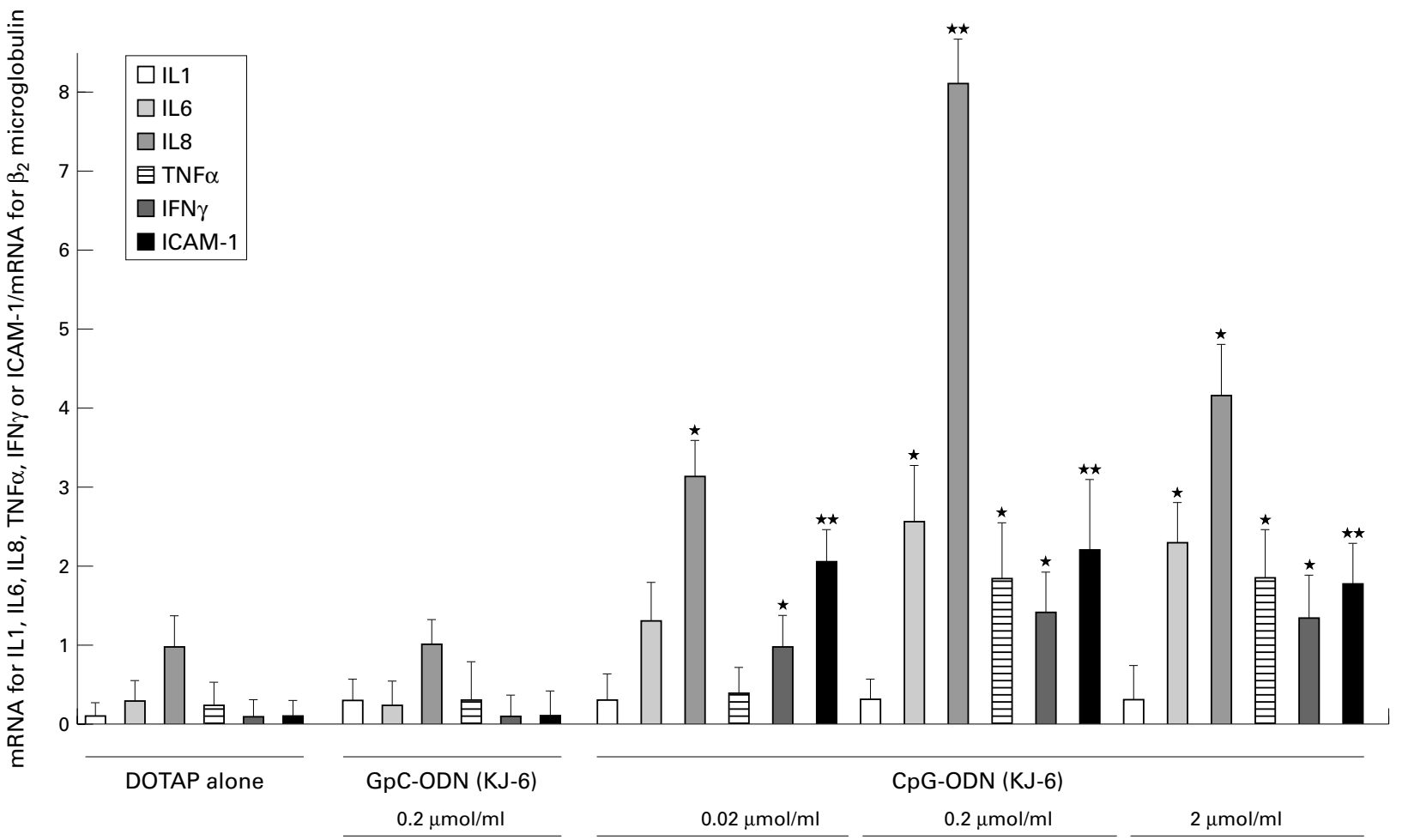

Figure 2 Interleukin 1 (IL1), IL6, IL8, tumour necrosis factor a (TNFa), interferon $\gamma$ (IFN $\gamma$ ), and intercellular adhesion molecule-1 (ICAM-1) $m R N A$ levels in endothelial cells (EC) transfected with a CpG-ODN (Kf-6) or GpC-ODN (Kf-6). The mean and standard deviation of cytokine $m R N A$ levels in EC transfected with $C p G-O D N(K \mathcal{F}-6)$ or $G p C-O D N(K \mathcal{F}-6)$ in five independent experiments using EC from five different sources is shown. There were no significant differences in IL1 mRNA levels between EC transfected with Cp G-ODN (KF-6) and those transfected with GpC-ODN (KF-6). IL6, IL8, TNFa, IFN $\gamma$, and ICAM-1 mRNA levels were significantly increased in EC transfected with Cp G-ODN (KF-6) compared with those transfected with $G p C-O D N(K \mathcal{F}-6)(p<0.05$ at 0.2 and $2 \mu \mathrm{mol} / \mathrm{ml}$ for IL6, $p<0.05$ at 0.02 and $2 \mu \mathrm{mol} / \mathrm{ml}$ and $p<0.01$ at $0.2 \mu \mathrm{mol} / \mathrm{ml}$ for IL8, $p<0.05$ at 0.2 and $2 \mu \mathrm{mol} / \mathrm{ml}$ for TNFa, $p<0.05$ at 0.02, 0.2 , and $2 \mu \mathrm{mol} / \mathrm{ml}$ for IFN $\gamma, p<0.01$ at 0.02, 0.2, and $2 \mu \mathrm{mol} / \mathrm{ml}$ for ICAM-1). ${ }^{\star} p<0.05,{ }^{\star} p<0.01$.

pathway, which requires endosomal translocation and maturation. ${ }^{13}$ A stress kinase, p38 mitogen activated protein kinase, was found to be activated by $\mathrm{CpG}-\mathrm{ODN}$ and induces the synthesis of IL6, IL8, TNF $\alpha$, and IFN $\gamma$ and the expression of ICAM-1 and VCAM-1. ${ }^{14} 15$

Proinflammatory cytokines such as IL1, IL6, $\mathrm{TNF} \alpha$, and IFN $\gamma$ are known to induce the expression of ICAM-1 on EC. Among these cytokines, expressions of mRNAs for IL6, $\mathrm{TNF} \alpha$, and IFN $\gamma$ were enhanced in EC transfected with $\mathrm{CpG}-\mathrm{ODN}$, but not with $\mathrm{GpC}$ ODN. Two mechanisms for the expression of ICAM-1 are proposed: (a) directly through p38 phosphorylation, and (b) indirectly through stimulation by IL6, TNF $\alpha$, and IFN $\gamma$; however, p38 phosphorylation and the effect of neutralisation of IL6, TNF $\alpha$, and IFN $\gamma$ were not examined in this study.

Considering that EC which had been incubated for three hours with both DOTAP and a synthetic ODN expressed the mRNA for ICAM-1, and the time lag in ICAM-1 expression on EC determined at 48 hours' incubation by flow cytometric analysis, both mechanisms may be implicated in the expression of ICAM-1 on EC.

As far as we know, no studies report the production of IFN $\gamma$ by EC. Therefore, we performed the experiment using an enzyme linked immunosorbent assay (ELISA) kit (ENDOGEN, Cambridge, MA, USA) for the detection of IFN $\gamma$ produced by EC. The supernatants of $1 \times 10^{6}$ EC cultured with DOTAP, CpGODN, or GpC-ODN for 24 hours were analysed for the amount of IFN $\gamma$. IFN $\gamma 9 \mu \mathrm{g} / \mathrm{ml}$ and $1 \mu \mathrm{g} / \mathrm{ml}$ was detected in the supernatant of EC cultured with $0.02 \mu \mathrm{mol} / \mathrm{ml}$ of CpG-ODN (KJ-6) and with $0.02 \mu \mathrm{mol} / \mathrm{ml}$ of $\mathrm{GpC}-\mathrm{ODN}$ (KJ-6), respectively (data not shown). EC cell line or other stimulation, such as lipopolysaccharide, will be required to confirm IFN $\gamma$ production by EC because the amount of IFN $\gamma$ produced by the EC in this study is small.

In conclusion, DNA fragments containing the CpG motif in the sera of patients with SLE may be implicated in vasculitis through activation of proinflammatory cytokines and expression of ICAM-1. However, further studies, using serum DNA without lipofection reagent, as was shown in a previous study, ${ }^{3}$ will be required to establish the participation of circulating DNA fragments in the pathogenesis of vasculitis in SLE.

We are grateful to Ms K Onuma and Ms Y Yamada for their technical assistance and Ms E Omata for her help in preparing this manuscript.

This work was supported in part by a grant from the Foundation for the Research Committee for the Treatment of Early Rheumatoid Arthritis, supported by the Japanese Ministry of Health and Welfare.

1 Krieg AM, Ae-Kyung Y, Matson S, Waldschmidt TJ, Bishop GA, Teasdale R, et al. CpG motifs in bacterial DNA trigger direct B-cell activation. Nature 1995;374:546-9.

2 Stacey KJ, Sweet MJ, Hume DA. Macrophages ingest and are activated by bacterial DNA. J Immunol 1996;157: 2116-22.

3 Sato Y, Miyata M, Sato Y, Nishimaki T, Kochi H, Kasukawa R. CpG motif-containing DNA fragments from sera of patients with systemic lupus erythematosus proliferate patients with systemic lupus erythematosus proliferate

4 Bird AP. CpG-rich islands and the function of DNA methylation. Nature 1986;321:209-13. 
5 Sato Y, Shishido H, Kobayashi H, Takeda J, Irisawa A, Miyata $M$, et al. Adjuvant effect of a 14-member macrolide antibiotic

6 Jaffe EA, Nachman RL, Becker CG, Minick CR. Culture of human endothelial cells derived from umbilical veins. Identification by morphologic and immunologic criteria. J Clin Invest 1973;52:2745-56.

7 Yamamoto T, Yamamoto S, Kataoka T, Tokunaga $\mathrm{T}$. Lipofection of synthetic oligonucleotide having a palindromic sequence of AACGTT to murine splenocytes enhances interferon production and natural killer activity. Microbiol Immunol 1994;38:831-6.

8 Chomczynski P, Sacchi N. Single-step method of RNA isolation by acid guanidinium thiocyanate-phenol-chloroform extraction. Anal Biochem 1987:162:156-9.

9 Choi Y, Kotzin B, Herron L, Callahan J, Marrack P, Kappler J. Interaction of Staphylococcus aureus toxin "superantigens" with human T cells. Proc Natl Acad Sci USA 1989; $86: 8941-5$

10 Gussow D, Rein R, Ginjarr I, Hochstenbach F, Seemann G Kottman A, et al. The human $\beta 2$-microglobulin gene. Pri-
mary structure and definition of the transcriptional unit. J mary structure and definition
11 Liang H, Nishioka Y, Reich CF, Pisetsky DS, Lipsky PE. Activation of human B cells by phosphorothioate oligodeoxynucleotides. J Clin Invest 1996;98:1119-29.

12 Yi AK, Tuetken R, Redford T, Waldschmidt M, Kirsch J, Krieg AM. CpG motifs in bacterial DNA activate leukocytes through the $\mathrm{pH}$-dependent generation of reactive oxygen species. J Immunol 1998;160:4755-61.

13 Hacker H, Mischak H, Miethke T, Liptay S, Schmid R, Sparwasser T, et al. CpG-DNA-specific activation of antigen-presenting cells requires stress kinase activity and is preceded by non-specific endocytosis and endosomal is preceded by non-specific endocytosis

14 Beyaert R, Cuenda A, van den Berghe W, Plaisance S, Lee JC, Haegeman G, et al. The p38/RK mitogen-activated protein kinase pathway regulates interleukin-6 synthesis response to tumor necrosis factor. EMBO J 1996;15: $1914-23$.

15 Tamura DY, Moore EE, Johnson JL, Zallen G, Aiboshi J, Silliman CC. p38 mitogen-activated protein kinase inhibition attenuates intercellular adhesion molecule-1 upregulation on human pulmonary microvascular endothelial cells. Surgery 1998;124:403-7.

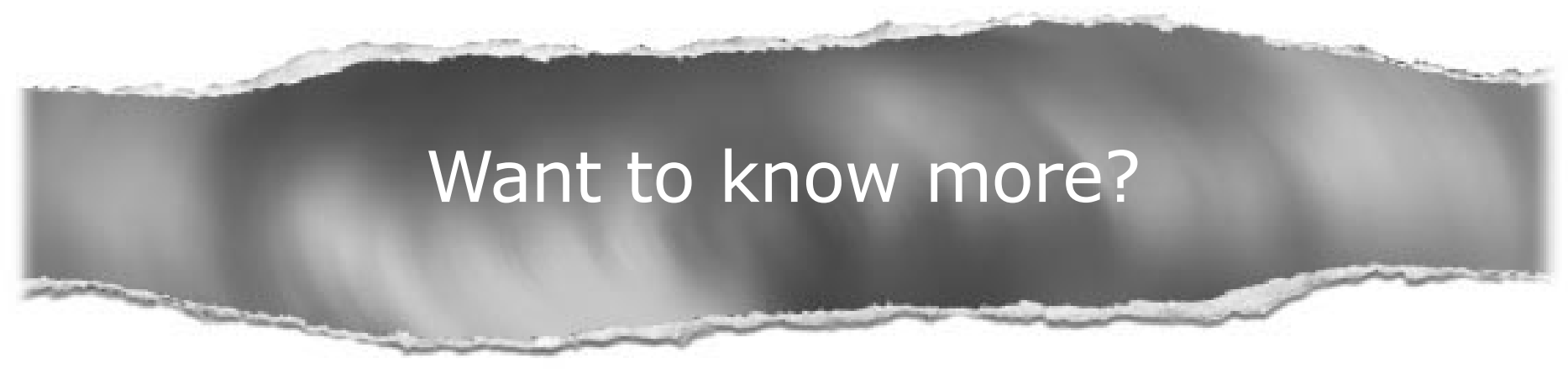

Data supplements

Limited space in printed journals means that interesting data and other material are often edited out of articles; however, limitless cyberspace means that we can include this information online.

Look out for additional tables, references, illustrations.

www.annrheumdis.com 